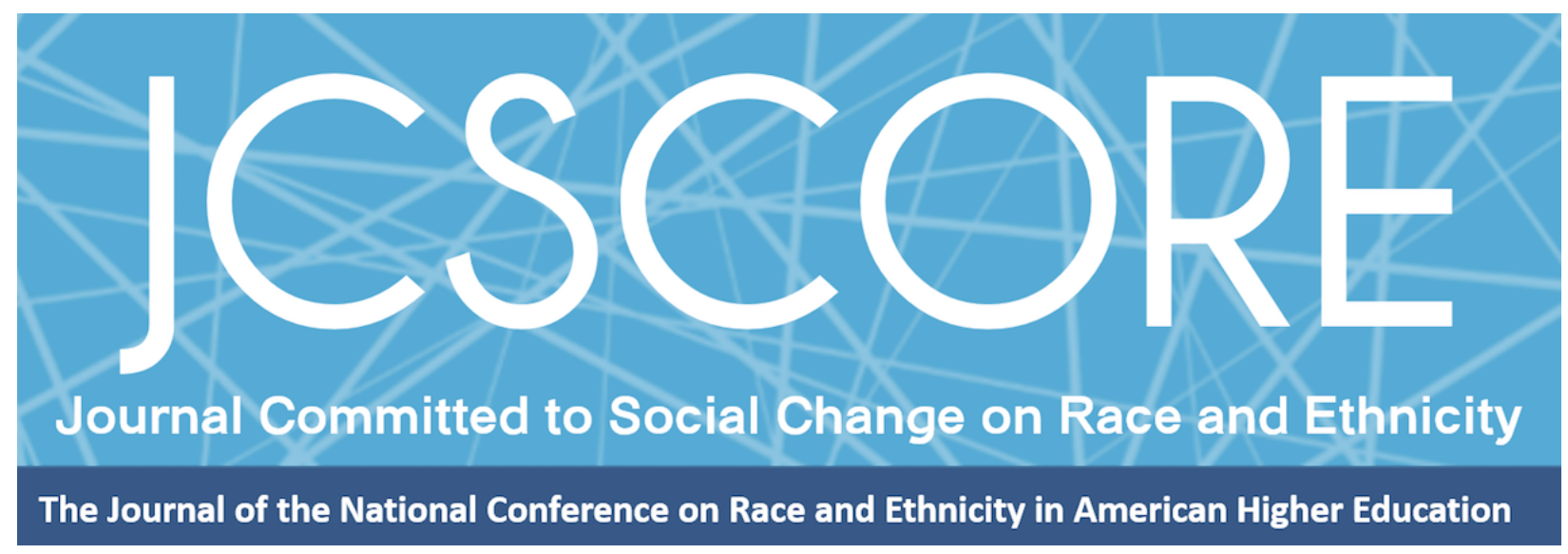

\title{
INTERSECTIONALITY AND AUTOETHNOGRAPHY: DEAFBLIND, DEAFDISABLED, DEAF AND HARD OF HEARING-LATINX CHILDREN ARE THE FUTURE
}

Carla García-Fernández

California State University, Northridge

Journal Committed to Social Change on Race and Ethnicity

Volume 6, Issue 1 | 2020

Copyright and Open Access

() 2020 Carla García-Fernández

(c) (i) (2)

This work is licensed under a Creative Commons Attribution-NonCommercial-ShareAlike 4.0 International License. Permission of the authors is required for distribution and for all derivative works, including compilations and translations. Quoting small sections of text is allowed as long as there is appropriate attribution and the article is used for non-commercial purposes.

The Journal Committed to Social Change on Race and Ethnicity (ISSN 2642-2387) is published by the National Conference on Race and Ethnicity (NCORE), a production of the University of Oklahoma, in partnership with the University of Oklahoma Libraries. 


\title{
Intersectionality and Autoethnography: DeafBlind, DeafDisabled, Deaf and Hard of Hearing-Latinx Children Are the Future
}

\author{
Carla García-Fernández \\ California State University, Northridge
}

\begin{abstract}
Deaf-Latinx $\mathrm{K}-12$ students are the largest group of racially minoritized students in the US, lagging far behind the complimentary proportion of Deaf-whites in obtaining degrees. Educational institutions have sustained and reproduced privilege and inequality patterns. This article explores how using Deaf-Latinx Critical Theory (Deaf-LatCrit) in educational research facilitates Deaf-Latinx epistemology, intersectionality, and cultural intuition in autoethnography. It effectively captured how I, a first-generation DeafChicana college student, navigated structural inequity in educational institutions. When extant literature and resources are limited, counter-stories must be included to expand knowledge about issues of educational equity, and promote accountability, decision-making, and action. Autoethnography validates my DeafChicana existence and calls for attention to multiple interlocking issues within the educational system. Deaf-LatCrit and autoethnography provided the platform for me to conduct this study, which derives primarily from my own higher educational experiences. This Deaf-Latinx ethnographic study provided me a valuable tool and a safe outlet to reflect on my academic experiences, and exposed five thematic concerns: raciolinguicism, interpreter quality, classroom exclusion, institutional and structural systems, and professional development. Recommendations are included to help individuals become more aware of unconscious and conscious discriminations so we can together improve support for DeafBlind, DeafDisabled, Deaf, and Hard of HearingLatinx students in higher education.
\end{abstract}

The first federally mandated study ${ }^{1}$ concerning academic achievements of racially minoritized Deaf ${ }^{2}$ students revealed they did indeed struggle compared to white

\footnotetext{
${ }^{1}$ This and other studies did not clearly indicate whether DeafBlind, DeafDisabled, and hard of hearing were included.

${ }^{2}$ The individuals within the U.S. Deaf community are not liberated from discrimination and oppression. Historically, Deaf people with sighted and abled-privileges have failed to recognize and honor tactile or pro-tactile signers who identify themselves as DeafBlind. There are also signers who identify as DeafDisabled, hard of hearing, or Late Deafened. I recognize there are also oral individuals who do not sign, and Deaf-Latinx who do not sign. When I discuss the larger community, I use the Signing Community to refer to DeafBlind, DeafDisabled, Deaf and hard of hearing people who use sign language. I acknowledge there are also oral, non-signing DeafBlind, DeafDisabled, Deaf and hard of hearing individuals too. However, the Signing community, particularly those who identify as Latinx/a/o, is the main focus for this paper.
} 
Journal Committed to Social Change on Race and Ethnicity | Volume 6, Issue 1 | 2020

Deaf students (Babbidge, 1964). Reflective of this failure to distinguish racially minoritized groups, educational scholars and researchers in Deaf education continue to place all K-12 Deaf students together as a single group, neglecting the educational experiences of racially minoritized Deaf students and promoting the concept of essentialism. As we pass the mid-point of 2020 , the same issue has now been repeated continuously for 56 years.

Nonetheless, over these years, a few scholars have addressed educational issues and challenges specifically related to racially minoritized Deaf students and their families (Anderson \& Bowe, 1972; Cohen, 1993, 1997; Delgado, 1984, 2000; Gerner de Garcia, 1993, 1995, 2000; McKay-Cody, 1998; Wu \& Grant, 2010). Yet, only recently have stories from DeafBlind, DeafDisabled, Deaf and hard of hearing students of Color been explored in several doctoral dissertations (García-Fernández, 2014; GuerreroCantor, 2019; Lawyer, 2018; McCaskill, 2005; Stapleton, 2016). Topics have included low expectations (which led to the practice of tracking, or placing racially minoritized students in low-ability groups), influencing students to take non-college-bound classes, awarding certificates of completion rather than high school diplomas, prejudicial attitudes that induced higher dropout rates (also known as pushouts), pedagogical biases, the prevalence of microaggressions, and Eurocentric curricula, which further isolated and marginalized these students.

In fact, very few racially minoritized DeafBlind, DeafDisabled, and Deaf and hard of hearing students are currently enrolled in higher education institutions (Foster \& Kinuthia, 2003; Guerrero-Cantor, 2019; Parasnis \& Fischer, 2005; Stapleton, 2016; Stapleton \& Croom, 2017; Williamson, 2007). More recently, data from an educational 
attainment study comparing academic achievement among racial/ethnic groups revealed Deaf-Latinx ${ }^{3}$ students are less likely to have completed high school and some college classes-just as data have also shown to be true for hearing Latinx students (Garbergolio et al., 2019). Only $12 \%$ of Deaf-Latinx (not including undocumented students) earned bachelor's degrees as opposed to $20 \%$ of white Deaf students (Garbergolio et al., 2019). The number of DeafBlind, DeafDisabled and hard of hearingLatinx students is unknown. Statistics such as these continue to paint a bleak picture for racially minoritized Deaf students and their families. Given these facts, the low numbers of these individuals pursuing higher education are not surprising, nor is the paucity of literature about DeafBlind, DeafDisabled, Deaf and hard of hearing-Latinx students and their educational experiences beyond high school. Historically, literature related to DeafBlind, DeafDisabled, Deaf and Hard of Hearing students of Color has been limited to academic research and publications in highly specialized peer-reviewed journals. In fact, there is only a single recent study of Deaf-Latinx undocumented immigrants (Guerrero-Cantor, 2019).

The purpose of this study was to examine the benefits of including Deaf-Latinx autoethnography in academic research. This study answers the following questions: 1) How can the method of Deaf-Latinx autoethnography benefit Deaf-Latinx related

\footnotetext{
${ }^{3}$ I self-identify as DeafChicana; the two identities cannot be separated. There is no right or wrong way in how we define ourselves. I use Latinx to refer to a label for gender nonbinary, Latina for self-identified women, and Latino for self-identifying men. I also want to acknowledge there is a controversy about the use of this term when discussing a specific group. In this paper, I use this term Latinx as an umbrella that includes: (1) people who connect with Caribbean Islands and/or heritage of Latin American descent and (2) elders, family members, or individuals who moved to the US from some Caribbean Islands and/or Latin America. Secondly, when I discuss the larger racial Signing Community, I use the term Signing Latinx Community.
} 
Journal Committed to Social Change on Race and Ethnicity | Volume 6, Issue 1 | 2020

educational research? 2) In what ways, can autoethnography reveal the experiences of linguistic and racialized oppression in higher education for a Deaf Latinx student?

\title{
Una lucha de fronteras I A Struggle of Borders
}

\author{
Because I, a mestiza, \\ continually walk out of one culture \\ and into another, \\ because I am in all cultures at the same time, \\ alma entre dos mundos, tres, cuatro, \\ me zumba la cabeza con lo contradictorio. \\ Estoy norteada por todas las voces que me hablan \\ simultáneamente. (Anzaldúa, 1987, p. 77)
}

As I swim through the words of Gloria Anzaldúa in her book, Borderlands/La Frontera (1987), a combination of prose and poetry written in Spanish and English, the parts I understand hit close to home. I am frustrated over not being able to better understand much of the Spanish. During my first year in elementary school, a teacher discouraged my mother from using Spanish since it would confuse my English lipreading training. So, I am challenged by the Spanish words because I did not have the chance to learn one of my home languages. I bought a used copy of Borderlands/La Frontera online. Used books can come with advantages. My copy has handwritten notes translating the Spanish text. Checking the accuracy helps me make sense of the concepts proposed by Anzaldúa. Halfway through the book, one of my sisters called me via video phone with great news. She knew I have been invested in researching and building our family tree for years. She was eager to tell me our parents (my father's side) had obtained more information about distant (past) relatives while they had been at a family reunion. The moment she signed, "Dad's grandfather was born in México," my heart leaped with joy since-a document revealed our father is Mexican. As we grew up in New México, we had been indoctrinated with the idea, "You are not a 
Journal Committed to Social Change on Race and Ethnicity | Volume 6, Issue 1 | 2020

Mexican, but Spanish.” Many individuals in New México, including my parents, disassociate with México, preferring to think of themselves as Spanish. Somehow this knowledge freed me to move further into connecting with that generation of my family.

After that conversation, I eagerly returned to Borderlands/La Frontera and soaked the pages with torrents of tears. My emotions ranged from sadness, to joy, anger, and even excitement. When I encountered the Nahuatl word, nepantla—an "inbetween" space that connects multiple worlds—I experienced a spiritual consciousness awakening. I realized I do not have to choose a singular space. Limiting myself to a single identity denies my "in-between" multiple identities. I live within a complicated but beautiful space and derive my own understanding of the world. Once a nepantlera, always a nepantlera. The process of embracing my multiple identities triggered a powerful spiritual transformation. I felt Anzaldúa's (1987) spirit when I read, "To survive the Borderlands you must live sin fronteras, be a crossroad" (p. 195). This statement guided me to the concept of intersectionality.

Critical Race Theory (CRT) emerged from the work of law and legal studies as scholars of Color challenged the discourse about issues of race and the eternal sprawling roots of racism and injustice in the U.S. legal system (Delgado \& Stefancic, 2001). The tenets of CRT recognize: (1) it is not possible to examine race and racism alone since they are interlocked with other forms of discrimination (gender, class, and many more) in multiple spaces known as intersectionality (Crenshaw, 1989, 1991; Delgado \& Stefancic, 2001); (2) dominant ideology is incompatible with the lived experiences of People of Color, and the claim of neutrality and/or silence reinforces white privilege and supremacy (Delgado \& Stefancic, 2001); (3) the concept of social 
Journal Committed to Social Change on Race and Ethnicity | Volume 6, Issue 1 | 2020

construction is promoted by arranging groups based on perceived different characteristics, granting privileges to white people as a group while denying privileges to others through racialization (Delgado \& Stefancic, 2001); (4) progress for racially minoritized groups often happens only when it benefits white people as well and is known as interest-convergence (Bell, 1980); and (5) sharing lived experiences among marginalized communities is a powerful way to counter historical white stock stories (Delgado, 1989).

CRT has gained popularity with scholars/activists in different disciplines as scholars of Color (Indigenous, Latinx, and Asian) found themselves in solidarity with CRT in terms of race and racism. However, the issues and priorities of their lived experiences differed, causing them to splinter from CRT's Black/white binary discourse (Delgado \& Stefancic, 2001). In the field of education, CRT portrayed additional issues with differential treatment and educational inequities (Ladson-Billings \& Tate, 1995; Yosso et al., 2001). These prejudicial barriers resulted in an opportunity gap between economically-advantaged whites, economically-disadvantaged students of Color, and marginalized immigrants. This resulting gap is typically defined by and reported in terms of dropout rates, suspensions, and/or incarcerations (Valencia, 1997, 2020). Latinx children, who have unique educational issues such as bilingual/multilingual, citizenship, and multiple identities, are caught in a similar yet more complicated and challenging dilemma (Yosso et al., 2001).

The work of these critical scholars has been monumental. As an individual born into a spoken Spanish and English Latinx household, I can easily relate to some Latino/a Critical Race Theory (LatCrit) issues. Nonetheless, the lived experiences and 
Journal Committed to Social Change on Race and Ethnicity | Volume 6, Issue 1 | 2020

issues of critical scholars of Color-in an aural based society—are deeply ingrained in hearing epistemology. As such, the discourse around language rights and accent discrimination focuses on spoken and written languages such as Spanish, Indigenous, or/and English, regardless of whether the specific context is related to education or the greater society. The automatic exclusion of sign language is not even a conscious decision. It is based on uniformed and unacknowledged biases held by scholars who have yet to recognize, much less explore, their own hearing privilege, as they enjoy entitlements linguistically inaccessible to Signing people. This is audism ${ }^{4}$ (Tuccoli, 2008).

Deaf epistemology—a way of knowing—possessed by Signing people (Holcomb, 2010) is revealed through stories about how audism has burdened Signing communities. Deaf Critical Theory (Gertz, 2003) borrowed CRT's tenets substituting audism for racism. I have faced audism daily since birth, so I know the issue of audism is just as serious and just as real as racism. Yet, my experiences as a DeafChicana, are not limited to simply these two forms of discrimination. My experiences include overlapping discriminations from multiple sources: ableism, audism, linguicism ${ }^{5}$, racism, and sexism in white and Latinx aural-based spaces, as well as white and Latinx Signing communities.

As mentioned earlier, my family home language of Spanish ${ }^{6}$ was stripped from me with the intention to assimilate me into the Eurocentric, dominant education ideology

\footnotetext{
${ }^{4}$ This term was introduced by Humphries (1977) as "a notion that one is superior based on one's ability to hear or behave in the manner of one who hears" (p. 12).

${ }^{5}$ Tove Skutnabb-Kangas (2014) coined linguicism as a form of discrimination based on language. ${ }^{6}$ The claim that only Spanish-speaking Latinx families are immigrants is problematic since Spanish has been spoken in the US, too, since colonization. Therefore, there are Spanish speaking Latinx families who were either born in the US, or im/migrated from their home country.
} 
Journal Committed to Social Change on Race and Ethnicity | Volume 6, Issue 1 | 2020

of speaking English orally as I signed in English order, known as Total Communication. This is in complete and utter opposition to the unique grammar and syntax rules of American Sign Language (ASL). A recent study showed $96 \%$ of Deaf children (irrespective of race or ethnicity) are born to hearing parents, only $30 \%$ of whom sign at home. Further, while $30 \%$ of Deaf children in the United States are Latinx, the number of hearing Latinx parents who sign at home is unknown (Gallaudet Research Institute, 2011). Failure to use Sign language in the presence of Deaf children during their early years causes language deprivation ${ }^{7}$ (Humphries et al., 2014), and contributes to cognitive delays and permanent mental health issues across their lifespans (Hall, 2017).

DeafDisabled and Deaf Latinx students report not having incidental learning and full access to world knowledge particularly about their family culture, history, and language since most of their hearing families do not sign at all times (GarcíaFernández, 2014). Other than school and home, community membership plays a role in how we come to understand our identity. When I associate with hearing Latinx people, I have always been questioned as to why I do not speak Spanish orally or write in Spanish, as if I am not Mexican enough. As I enter the Signing space, the discourse is often about the beauty of Deaf culture and ASL, which I am enculturated to. However, Eurocentric Deaf-related artifacts, videos, textbooks, and posters are not always relatable to me since I do not find anyone like me represented in them. Basically, the discourse reinforces the concepts of: "I do not see color," "We all are Deaf Americans," "We are Deaf, period," or "We are Deaf first over any other identities." Whenever I development. 
Journal Committed to Social Change on Race and Ethnicity | Volume 6, Issue 1 | 2020

speak up, I get stock white stories (Delgado, 1989) and stock white Deaf stories, which are simply explanations by dominant individuals/groups to justify their privileged positions.

Different from DeafCritTheory, Deaf-Latinx epistemology empowers Signing Latinx individuals to present their unique voices. Their stories counter the limitation of traditional audistic and Eurocentric Deaf epistemologies (Holcomb, 2010) in educational research. It also recognizes the value of Deaf-Latinx households with their "funds of knowledge" (Moll et al., 1992, p. 133), which reveal the richness of history, home language(s), cultural values and traditions, occupations, and personal skills of family members and friends within both home (García-Fernández, 2014) and social activities beyond family. For these reasons, I propose to use Deaf-Latino ${ }^{8}$ Critical Theory (DeafLatCrit) to reclaim the lived experiences of Signing Latinx students and their families (García-Fernández, 2014). Deaf-LatCrit consists of four fundamental tenets:

intersectionality, challenging dominant ideologies, consciousness, and storytelling.

The first tenet intersectionality reveals the limitations of the singular Deaf identity discourse when referring to Deaf-Latinx individuals and their unique ways of knowing. A growing number of scholars in the field of Deaf-related disciplines have compared audism with racism. This simplistic association promotes the concept of whitewashing the experiential knowledge of Signing People of Color. The second tenet acknowledges tightly enmeshed, systematic, institutional, and individual forms of racism as one of the dominant ideologies to be challenged, and linguicism as another. Deaf-Latinx students

\footnotetext{
${ }^{8}$ Latina/Latino is the term originally used in the title of my dissertation. Over time, however, the community discourse - particularly within academia - has evolved to promote inclusive, gender-neutral terms that are sensitive to and considerate of non-conforming individuals. I acknowledge this advancement and align with the new term, LatinX.
} 
Journal Committed to Social Change on Race and Ethnicity | Volume 6, Issue 1 | 2020

and their families are descendants of multilingual people whose ancestors spoke Indigenous languages and were forced to adopt colonizers' languages like Spanish and subsequently English. Parents of Deaf-Latinx people were often accused of not learning sign language without recognizing the historical pain of multiple language loss.

Consciousness, the third tenet, is part of the decolonization process in which one experiences an awakening, often through education. It involves engaging in ongoing activities such as unlearning, relearning, re-educating, resisting, and negotiating as Deaf-Latinx people learn about themselves through their home culture, history, and community. This process strengthens self-awareness and embraces multiple overlapping identities. Lastly, storytelling, the fourth tenet, creates a space where true Deaf-Latinx ways of knowing are shared and distributed through stories and counterstories. Deaf-LatCrit stories and counter-stories educate others and supersede distorted or false claims. Most importantly, as seen in our history, stories have been shared among our ancestors as part of an "essential tool to their own survival and liberation" (Delgado, 1989, p. 2436). It is, therefore, our duty to include stories about ourselves that recognize both common and unique experiences. Intersectionality is the primary purpose of Deaf-LatCrit Theory because it moves analysis of the lived experiences of Deaf-Latinx community beyond a singular identity and singular discrimination such as Deaf and audism.

\section{Methodology}

Scanty Deaf-Latinx education-related literature means a shortage of resources and action. To address this important gap in education literature, counter-storytelling can reveal traditional dominant discourses. Therefore, I challenge the status quo by 
Journal Committed to Social Change on Race and Ethnicity | Volume 6, Issue 1 | 2020

presenting methodological Deaf-Latinx autoethnographic research to expand DeafLatinx-related literature through counter-narratives. Counter-storytelling emphasizes the value of Signing Latinx epistemology and recognizes the sacredness of viewpoints brought to the space of Signing/Deaf Latinx research. Counter-storytelling contains personal narratives, other people's narratives, and composite narratives from multiple sources (Solórzano \& Yosso, 2002). Personal narratives are a collection of lived experiences, community memory, and collective experience. Deaf-LatCrit recognizes the value of autoethnography and Delgado Bernal's (1998) cultural intuition. Cultural intuition rethinks Strauss and Corbin's (1990) proposed theoretical sensitivity with four main sources: personal experiences, professional experiences, available literature, and the process of research analysis. Delgado Bernal (1998) eventually conceded community memory and collective experiences are included in personal experiences; and years later, she and her colleagues recognized the important link between spirituality and activism. Therefore, they included it as one of the cultural intuition sources (Calderón et al., 2012). I used my academic experiences and my cultural intuition to source and gather available literature, document my own personal professional experiences, and reflect on the process of decolonizing.

The Deaf-LatCrit framework provided me with a space where I could explore my academic experiences as a first-generation DeafChicana college student. For four months, I gathered sources by jogging my memories, journaling, talking with family members and colleagues, reviewing my dissertation, and skimming through email correspondences, and letters of grievance. Secondly, I identified similar themes among undocumented Latina Deaf postsecondary students living in the U.S. (see Guerrero- 
Journal Committed to Social Change on Race and Ethnicity | Volume 6, Issue 1 | 2020

Cantor, 2019). I recognize my U.S. citizenship status and ability to obtain financial support afford me privileges that differ from their experiences. As I worked, Deaf-Latinx students confided in me about their academic experiences and I found them relevant as collective experiences. The entirety of this process did not go without tears, smudging sage, and meditation, as I remained focused during the full analytical process. These processes are organic and messy—Deaf-LatCrit stresses the importance of using the intersectionality lens. My analysis involved first digesting and typing out my experiences, reflecting on each incident, sorting, and making notes until themes of discrimination emerged in various settings. These settings included classrooms, meeting rooms, college lecture halls, conference sites, and Internet-based communications (emails and videophone meetings). I have included the most profound academic experiences below in italics with institutions abbreviated in parentheses.

I am impelled by the urgency of this study. The longer we wait to reveal our own personal challenges in higher education, the greater the number of Deaf-Latinx students who will remain vulnerable to similar discriminations.

\section{Journey of a First-Generation DeafChicana College Student}

I was drawn to enroll in and earned degrees from three different four-year institutions. I earned a Bachelor of Arts in Child Development from Gallaudet University (GU) in Washington, DC, the only liberal arts university in the world for the deaf; a Master of Arts in Language, Reading, and Culture from the University of Arizona (UA) in Tucson; and a Ph.D. in Cultural Studies in Education at the University of Texas (UT) in Austin. As part of my professional development, I have also taken a course at the University of New México in Albuquerque and several courses at the Santa Fe 
Journal Committed to Social Change on Race and Ethnicity | Volume 6, Issue 1 | 2020

Community College in New Mexico. Regardless of each institution's reputationGallaudet University is known as the "Deaf Mecca," and four out of five of the others are Hispanic Serving Institutions—none was free from oppression. The data in this study revealed several discriminatory thematic concerns: raciolinguistic, interpreter quality, classroom exclusion, institutional and structural systems, and professional conferences.

\section{Raciolinguistic}

Deaf-LatCrit acknowledges the dominant interlocking ideologies of racism and linguicism seem to go hand-in-hand. The concept of raciolinguicism is a natural, albeit disheartening, development. Rosa and Flores (2017) proposed a raciolinguistic perspective as an interrogation of the "historical and contemporary co-naturalization of language and race" (p. 622). This perspective involves ongoing deficit views of both culture and language with an ideology that "links the white speaking and listening subject to monoglossic language ideologies, which position idealized monolinguialism in a standardized national language as the norm to which all national subjects should aspire" (Flores \& Rosa, 2015, p. 151). The raciolinguistic perspective is also pervasive in Signing Communities globally.

During my first semester, I participated in many introductory presentations and activities. I recall attending a presentation by a Deaf faculty member on the topic of ASL. When it was time for Q\&A, I stood up with a question. Instead of giving me an answer, the presenter asked why I was not signing in ASL. (GU)

As an individual born to a hearing, Spanish and English-speaking family, I was not exposed to ASL 24/7 at home. My parents adopted a prescriptive ideology, expecting me to simultaneously speak and sign English. But with my siblings, I used a 
Journal Committed to Social Change on Race and Ethnicity | Volume 6, Issue 1 | 2020

mixture of home signs ${ }^{9}$ and ASL. Not surprisingly, most of my teachers were white and hearing; they required me to talk and sign at the same time in their classrooms. Again, just like my siblings, when no teachers or authority figures were present, my Deaf peers and Deaf residential staff members used ASL - only. Yet, my experiences and language use are vastly different from those of a presenter I know who was born to a Deaf family, possessed language privilege, and had the ability to use ASL at home. Deaf-LatCrit completely supports full access to signed languages, but without the raciolinguistic perspective positioned on the ability to sign exactly according to the expectations of white middle-class Deaf people who have been instilled with language entitlement and superiority (Ruiz-Williams et al., 2016; Sedano, 2001). The learning experience of Deaf children is shaped by watching how generations of Deaf adults behave and talk.

White Deaf students criticized my cultural-related home signs for New México's state vegetable, the chile, as well as tortillas, tamales, beans, sopapillas, Spanish, México, Mexican, etc. (GU)

Subtractive approaches diminish educational equity and we must monitor the issue of appropriateness in additive approaches (Flores \& Rosa, 2015).

Appropriateness connects to "prescriptive ideologies, which dictate there is one correct way of using languages and arbitrarily privilege particular linguistic practices while stigmatizing others" (Flores \& Rosa, 2015, p. 150). And, there is another way deficit views prevent full access to information discussed in educational settings: using sign language interpreters.

\footnotetext{
${ }^{9}$ Prior to being exposed to sign language, Deaf children born to hearing parents came up with home signs to communicate their thoughts. They were viewed as unintelligent, having no language-longstanding racialized ideologies.
} 
Journal Committed to Social Change on Race and Ethnicity | Volume 6, Issue 1 | 2020

\section{Interpreter Quality}

A professor of color and students were discussing racism and inequity in the U.S. education system. A white female interpreter looked at me and signed, "The discussion about racism is too much for me." (UT)

When I saw the interpreter's comment, I immediately thought to myself, Oh those white tears! Most sign language interpreters are white (Registry of Interpreters for the Deaf, 2018) and their cultural competence relative to interpreting is often based on a Eurocentric Deaf cultural perspective. Foster (2018) suggests interpreters work on "[l]istening to Deaf people without being defensive, apologizing when called for, taking responsibility for our actions, and learning from mistakes will go far to rebuild the delicate trust necessary for hearing interpreters to work effectively with the Deaf community" (para. 11). This statement again proposes a Deaf versus hearing dualism conversation without recognizing other possible forms of discrimination. It is not only about hearing and Deaf, but also Signing Black, Indigenous, or other People of Color. It can be very exhausting and sometimes, saying nothing helps me reserve my energy for my academic work. Another time I had to address an interpreter who attempted to hold her power.

It was an honor to be in a class taught by a well-known, a globally respected Mexican male professor who spoke at length. White woman Interpreter \#1 repeatedly stumbled and listened attentively until she figured out all the information, then translated, but only a brief summary. I told her I was unable to follow her and asked her to repeat. Meanwhile, the professor continued to talk. Interpreter \#1 became nervous and continued to be unclear. I asked her if she could step aside and let her teammate take over. She signed, "No." Seconds became minutes. She repeatedly signed, "No." I signed, "Ok, I do not want you to be the interpreter for this class. Get out." As she angrily got up and left, white woman Interpreter \#2 took over. My professor noticed the switch and paused to let Interpreter \#2 catch up. (UA) 
Journal Committed to Social Change on Race and Ethnicity | Volume 6, Issue 1 | 2020

First, this interpreter disrespected my right to education by abbreviating the information shared in class. Secondly, the interpreter failed to abide by the interpreter's code of professional conduct by ignoring my request to give up her seat. Annamma et al. (2013) suggested whiteness and ability as properties present economic gains to those who align with white and ability. Unfortunately, this was not my first nor last experience with property privilege.

At an out-of-town conference, I walked into a session and saw two white female interpreters waiting. One of the interpreters immediately approached me and pointed to a seat indicating I was to sit there. I thanked her and replied that I would decide where to sit. During the session, we sat in a circle discussing our journeys as graduate Students of Color. When it was my turn to talk, I discussed my data collection progress. I signed "dissertation," however, I caught the same interpreter pronouncing, "write." I quickly corrected her, fingerspelling, "d-i-s-s-e$r$-t-a-t-i-o-n" and she was like, "Oh! surprised." She sat up straight and translated much more professionally. (UT)

First, I often wonder whether interpreters will be a good fit before I meet with them. I question whether they are fluent in ASL and can translate accurately. I consider whether they can relate to my racial/ethnic identity or community. If I have a good feeling about the interpreter, it is one less thing I have to worry about. I do believe it is important for me to know my rights. Other than interpreters, classroom exclusion is also a challenge.

\section{Classroom Exclusion}

Beyond these experiences with sign language interpreters, six occurrences are described below that show how professors and students in classrooms have the power to create hostile learning environments.

On the first day of class, a woman professor of color was reading a handout that had been distributed in class. I quickly skimmed it but could not finish since I did not want to miss watching the interpreter signs. After class, I asked for an appointment with the professor via video relay service along with a sign language interpreter whom I (but not the professor) could see on the screen; the professor could hear the interpreter as she interpreted. I attempted to explain the challenge 
of reading class handouts or PowerPoint presentations and watching a sign language interpreter at the same time and asked if the handouts could be shared possibly a day, or even just a few hours prior to class. The professor interrupted saying, "I am not responsible, you will need to contact the disability services" and cut our phone conversation short. (UT)

Hearing students or professors often initiated their conversations by saying to the sign language interpreter(s), "Tell Carla/her that...," "Tell Carla/her to...," or "Have Carla/her..." This always makes me feel like I am not someone since they do not directly talk with me. (UA/UT)

In a large group discussion with other teachers in training, I was asked to discuss my experience growing up as a Deaf person. I responded that it feels natural just like being born with brown hair and eyes. A white hearing male student said I was "denied a very important sense" and I was "dismissing its absence as a mere cosmetic fluke". (SFCC)

Upon my arrival in a classroom, I sat in a front seat close to where the interpreters stood. This woman professor of color seemed puzzled. She asked why the interpreter was standing in the front (implying only the professor should be up front). I explained I needed to see the interpreter next to her since it is how I grasp information best. She told us we should sit in the back of the classroom. (UT)

On the first day of class with permission from the professor, I usually stand up and ask for a volunteer to take notes since it is not possible for me to write down notes and watch interpreters at the same time. Regardless of whether ASL is my primary language, my request for a computer assisted real-time translation (CART) for notes was denied-I was forced to choose one or the other. In one class, a paid a student note taker (UA) took notes for me; another time, a student volunteer (UT) offered to take notes. When I received the notes, some were very clear and detailed, while others were awful and superficial, or the handwriting was difficult to read. When I expressed my concern, it was suggested I look for someone else. (UT)

Many hearing students and professors in graduate classes never fail to look at whoever speaks orally ...but not me. When I signed, instead of looking at me, students and professors looked at the working interpreter standing in the front of the classroom translating from ASL to spoken English. When the professor spoke, I attentively watched the interpreter sign. Due to my visual attention being heightened in my peripheral vision, I know I am being stared at. (UA/UT/UNM/SFCC) 
Journal Committed to Social Change on Race and Ethnicity | Volume 6, Issue 1 | 2020

Attending classes can be intimidating since I often feel excluded. I have to work hard to prove to faculty, students, and interpreters I am capable by attending, participating, and completing assignments. If one thing goes wrong-like the interpreter, notetaker, or closed captioning — I fear being viewed as a burden. Then if I request something else, my racial/ethnic and Deaf identity can be viewed negatively as if I am lazy, not trying hard enough. This can be very stressful and tiring. Annamma et al. (2013) proposed "the legacy of historical beliefs about race and ability, which were clearly based on white [and hearing] supremacy, have become intertwined in complex ways that carry into the present day" (p. 2). Classrooms are not the only spaces that can be oppressive. Looking beyond the classroom, we see how subtly pervasive oppression is in a myriad of institutional and structural systems.

\section{Institutional and Structural Systems}

During registration for graduate classes, I was instructed to request sign language interpreters for my classes. Once the request was submitted, I was automatically classified as an individual with a dis/ability by the university's Disability Resource Center. It took me a while to comprehend how intimately language is connected to this term, dis/ability. Nonetheless, I chose not to challenge my status with the Disability Resource Center since I feared losing the privilege of having interpreters in my classes. (UA)

Looking back to that day when I was instructed to submit a request for a sign language interpreter, I feel I have been forced to identify as an individual with a dis/ability and utilize unfamiliar terms such as "hearing loss" or "can't hear." I cannot connect with those terms. They hold no meaning for me-I was born deaf. It seems like I always have to justify my preference to access world knowledge through my primary language. I have continually been placed under a microscope by authorities who promoted Aristotle's deeply rooted ideology that acclaims five human senses. 
Journal Committed to Social Change on Race and Ethnicity | Volume 6, Issue 1 | 2020

Historically developed social constructions are deeply instilled in human thoughts.

Those embedded views cause individuals who have been othered to be bodily

manipulated by dominant authorities to gain recognition or/and rewards. Mexican deaf

women navigating college and living as undocumented also report they cannot relate to

this term "disabled" (Guerrero-Cantor, 2019). The dichotomy of "deaf versus disabled"

has been a long, ongoing discussion in Signing communities. Based on my knowledge, there is no study on this topic.

Below is another example of how disability services in higher education promote multiple forms of discrimination such as racism, ableism, linguicism, and audism.

In some Mexican American Studies (MAS) Graduate Portfolio courses, students code switched (used both Spanish and English). I had no problem since Spanish is part of me. The bilingual sign language interpreter signed, "Sorry, s/he [they] is [are] speaking Spanish." And the more frequently the Latinx students code switched, the more often the interpreter would say, "Sorry." I believe a student's primary language should be comfortably used in the classroom. However, I became lost and was unable to be part of the conversation, so I sent in a request for a trilingual interpreter (ASL, English, and Spanish) for the remainder of the semester. My request was denied by disability services. I kept asking for one and finally had a meeting with an administrative supervisor. During the meeting, I argued that declining the request for a trilingual interpreter disempowered me from participating in class discussions. I was asked, "How much Spanish do you know?" I knew that was an inappropriate question. At last, a trilingual interpreter was provided to team with an interpreter. The conversation in the class continued with ASL, Spanish, and English and it was a beautiful experience. Months later, disability services complained, "Trilingual interpreters are too expensive." (UT)

DeafLatCrit recognizes the problem of disability services not honoring multiple languages. Annamma et al. (2013) reported disability services neglected the issue of racism and promoted exclusion as opposed to inclusion. In my example situation, suppose Latinx students had been commanded to speak English only. This is easily identified as racism. Had I been denied trilingual interpreters, that would have also constituted racism since I would have been denied access to the spoken Spanish 
Journal Committed to Social Change on Race and Ethnicity | Volume 6, Issue 1 | 2020

environment (and, in fact I was denied such access prior to the trilingual interpreter).

This situation was very stressful and required me to seek additional support from my advisor, therapist, colleagues, and friends to deal with this instance of racism and linguicism.

I, and two colleagues, were interested in speaking at a conference on campus. Interpreters were requested three weeks in advance through the university's disability services. During the wait, I followed up to see how the interpreter search was proceeding and was told they were waiting for a response from an agency off campus since the university staff interpreters were unavailable. I experienced high levels of stress because a few days before the conference we still had no interpreters. I contacted the agency and asked when disability services had submitted the interpreter request. They had only just received the request! This did not allow sufficient time to prepare the interpreters to work effectively with us. As my information was being translated by the interpreters, I was concerned about accuracy. I could tell (based on body language, posture, fidgeting, etc.) the message was not affecting the audience and video viewers as intended and was worried it would not leave a positive impression of my work. Later, I asked a trusted interpreter to review the video and was told the working interpreters had not interpreted my message clearly. This could leave gloomy marks on my identity, CV, and future networking opportunities. (UT)

I was dissatisfied with the lack of accountability from disability services. Its structure is based on white supremacy and "ability and dis/ability are perceived and created based on ideologies of race and located within social and institutional structures as well as personal attitudes" (Annamma et al., 2013, p. 7). Similar attitudes are expressed by students, faculty, student body government, support service staff, provosts, presidents, and the boards of trustees of the universities.

After Elisabeth Zinser, a hearing individual, was appointed as the new president, Student Body Government Deaf student leaders met with the Board of Trustees Chair, Jane Bassett Spilman, to express their disappointment and disagreement. The ability of a "Deaf" person to lead a university as president was questioned by 
Journal Committed to Social Change on Race and Ethnicity | Volume 6, Issue 1 | 2020

Spilman who commented, "Deaf people are not ready to function in a hearing world" (Houston, 1988, para. 18). (GU)

This was when I realized the real problem within higher education institutions. We must challenge why certain board members are selected. What is their intention in serving as a board member? Interest convergence plays into the field of whiteness and hearingness. I felt just like others who report not feeling fully included in the historical movement since the leaders of the Student Body Government were all white (Stuart \& Gilchrist, 1990). I was caught in double marginalization. Higher education institutions often stress the importance of collaboration and networking such as professional conferences however, ongoing challenges are often overlooked.

\section{Professional Development}

Toward the end of my doctoral program, I was encouraged to attend conferences as part of professional development like the American Education Student Association or American Education Research Association to present my work, get feedback from other scholars, develop a network, and explore potential employment opportunities.

I submitted a proposal for the America Education Student Association conference and simultaneously requested sign language interpreters. I knew early notice would help the conference committee prepare for my presentation and the workshops I was interested in participating. I was told I was limited to two workshops per day due to limited funding. I submitted a letter discussing the problem of differential treatment and the importance of inclusion. Later my proposal paper was denied. (UT)

DeafLatCrit recognizes that not just one, but numerous overlapping discriminations suppress Deaf-Latinx and other marginalized BIPOC students from achieving academic success. Therefore, DeafLatCrit pushes for universal design by making sure interpreters, notetakers, and communication access real-time translation 
Journal Committed to Social Change on Race and Ethnicity | Volume 6, Issue 1 | 2020

(CART) reporters are part of the team. These same obstacles, discriminations, and marginalizing attitudes are just as prevalent in the workforce.

[B]ecause postsecondary education systematically rejects universal design and has deeply embedded dominant ideologies like [racism], audism and linguicism into their practice, Deaf students [particularly Deaf-Latinx] have in turn been placed in inferior and subordinate positions of power. This means there are limits and barriers subjected onto them and hinder them from attaining a just educational experience. This can be recognized through a cumbersome and complex process of requesting accommodations. (Guerrero-Cantor, 2019, p. 86)

\section{Reflection and Recommendations}

My analysis answered both questions. First, how can Deaf-Latinx autoethnography benefit Deaf-Latinx related educational research? Deaf-Latinx autoethnography reveals educational research benefits. It has initiated new narratives among DeafBlind, DeafDisabled, Deaf, and Hard of Hearing-Latinx students and allowed collective autoethnography to expand literature. Second, in what ways can autoethnography reveal the experiences of linguistic and racialized oppression in higher education for a Deaf Latinx student? Autoethnography has allowed me, as an individual, to discuss situations that were clearly rooted in male, white hearing, and white Deaf supremacy (Annamma et al., 2013). Generally, diversity tends to be defined by race, ethnicity, gender, or sexual orientation, providing dis/ability and support services according to each specific circumstance.

Further, the idea of utilizing autoethnography in research also calls attention to how the dominant ideologies of racism and linguicism have successfully used a raciolinguistic perspective to assimilate ideologies and permit them to operate within higher education institutions. This is not to be taken lightly. Finally, Deaf-Latinx autoethnography has encouraged me to make peace with my awakening 
Journal Committed to Social Change on Race and Ethnicity | Volume 6, Issue 1 | 2020

consciousness—not an easy task since my emotional state is messy. The process of embracing my multiple, fragmented identities, sitting at the edge of my own Borderlands, is fraught with triggers and traumas that are sometimes unexpectedly and too easily kindled.

In summary, Deaf-LatinxCrit Theory has offered me a safe space to conduct research using an intersectionality framework that recognizes and values my DeafLatinx epistemology. The cultural intuition of Deaf-Latinx autoethnography provides a tool to reveal historical differential treatment based on biases and discrimination. This does not debunk the white supremacy of state educational-related laws, policies and rules of the institutions, student services, quality of faculty members and sign language interpreters, or curriculum and pedagogy.

The quality of interpreters' training, certification, personal, and professional experiences are crucial to assure Signing DeafBlind, DeafDisabled, Deaf and hard of hearing-Latinx students have equal access to presented information. Interpreter training programs must commit to culturally responsive interpreting and become aware of cultural and linguistic issues within the Signing communities. Secondly, faculty members must genuinely commit to monitor their biases and work on them if needed. They must consider Signing DeafBlind, DeafDisabled, Deaf and hard of hearing Latinx students as valuable members of the class. They should be critically conscious and take pride in providing a learning environment that is both unique and inclusive, encouraging everyone to participate regardless of whether they use signed or spoken language. This also gives faculty an opportunity to improve their understanding of how they can promote universal design. Thirdly, the university's disability services, and the campus as 
Journal Committed to Social Change on Race and Ethnicity | Volume 6, Issue 1 | 2020

a whole, must take an open and powerful stand against a singular identity discourse and acknowledge multiple overlapping identities among students they serve, regardless of dis/abilities.

\section{Conclusion}

I challenge higher education institutions' administrators, faculty members, and staff to commit to dismantle white and Hearing supremacy. We all have social and community accountability to eliminate obstacles, whether physical or attitudinal, that prevent Deaf-Latinx students and faculty members from being successful. This effort requires honoring our requests and listening to feedback with open hearts and minds. All individuals in the room need to embrace this mindset shift and pass it on by practicing the same kind of activism that evokes love and compassion for all. This is what makes us better human beings.

We need to commit to having the number of DeafBlind, DeafDisabled, Deaf and Hard of hearing-Latinx graduates and faculty members grow.

¡Sí, se puede! [Yes, we can!] 
Journal Committed to Social Change on Race and Ethnicity | Volume 6, Issue 1 | 2020

\section{References}

Anderson, G., \& Bowe, F. (1972). Racism within the Deaf community. American Annals of the Deaf, 117(6), 617-619.

Annamma, S. A., Connor, D., \& Ferri, B. (2013). Dis/ability critcial race studies (DisCrit): Theorizing at the intersections of race and dis/ability. Race Ethnicity and Education, 16(1), 1-31.

Anzaldúa, G. (1987). Borderlands, La Frontera: The new Mestiza. Aunt Lute Books.

Babbidge, H. D. (1964). Education of the deaf: A report to the Secretary of Health, Education, and Welfare by his Advisory Committee on the education of the deaf. U.S. Department of Health, Education, and Welfare.

Bell, D. (1980). Brown v. Board of Education and the interest-convergence dilemma. Harvard Law Review, 93, 518-533.

Calderón, D., Delgado Bernal, D., Pérez Huber, L., Malagón, M., \& Vélez, V. N. (2012). A Chicana feminist epistemology revisited: Cultivating ideas a generation later. Harvard Educational Review, 82(4), 513-539.

Cohen, O. P. (1993). Multicultural education and the Deaf community: A conversation about survival. A Deaf American Monograph, 43, 23-27.

Cohen, O. P. (1997). Giving all children a chance: Advantages of an antiracist approach to education for Deaf children. American Annals of the Deaf, 142(2), 80-82.

Crenshaw, K. W. (1989). Demarginalizing the intersection of race and sex: A black feminist critique of antidiscrimination doctrine, feminist theory and antiracist politics. University of Chicago Legal Forum, 1, 139-167.

Crenshaw, K. W. (1991). Mapping the margins: Intersectionality, identity politics, and violence against women of color. Stanford Law Review, 43(6), 1241-1299.

Delgado Bernal, D. (1998). Using a Chicana feminist epistemology in educational research. Harvard Educational Review, 68(4), 555-582.

Delgado, G. L. (1984). Hearing-impaired children from non-native-language homes. In G. L. Delgado (Ed.), The Hispanic Deaf: Issues and challenges for bilingual special education. Gallaudet University Press.

Delgado, G. L. (2000). How are we doing? In K. Christensen (Ed.), Deaf plus: A multicultural perspective. Dawn Sign Press.

Delgado, R. (1989). Storytelling for oppositionists and others: A plea for narrative. Michigan Law Review, 87, 2411-2441.

Delgado, R., \& Stefancic, J. (2001). Critical Race Theory: An introduction. New York University Press.

Flores, N., \& Rosa, J. (2015). Undoing appropriateness: Raciolinguistic ideologies and language diversity in education. Harvard Educational Review, 85(2), 149-171. doi:10.17763/0017-8055.85.2.149

Foster, M. (2018). Erosion of trust: Sign language interpreters and hearing privilege [Blog post]. https://streetleverage.com/2018/10/erosion-of-trust-sign-languageinterpreters-and-hearing-privilege/

Foster, S., \& Kinuthia, W. (2003). Deaf persons of Asian American, Hispanic American, and African American backgrounds: A study of intraindividual diversity and identity. Journal of Deaf Studies and Deaf Education, 8(3), 271-290.

Garbergolio, C. L., Palmer, J. L., Cawthon, S., \& Sales, A. (2019). Deaf people and educational attainment in the United States: 2019. U.S. Department of Education, 
Journal Committed to Social Change on Race and Ethnicity | Volume 6, Issue 1 | 2020

Office of Special Education Programs, National Deaf Center on Postsecondary Outcomes.

García-Fernández, C. M. (2014). Deaf-Latina/Latino critical theory in education: The lived experiences and multiple intersecting identities of deaf-Latina/o high school students (Doctoral dissertation), University of Texas Austin.

http://hdl.handle.net/2152/25088

Gerner de Garcia, B. (1993). Addressing the needs of Hispanic Deaf children. In K. M. Christensen \& G. L. Delgado (Eds.), Multicultural issues in Deafness. Longman Publishing Group.

Gerner de Garcia, B. (1995). ESL applications for Hispanic Deaf students. The Bilingual Research Journal, 19(3 \& 4), 453-467.

Gerner de Garcia, B. (2000). Meeting the needs of Hispanic/Latino Deaf students. In K. M. Christensen \& G. L. Delgado (Eds.), Deaf plus: A multicultural perspective. Dawn Sign Press.

Gertz, G. (2003). Dysconscious audism \& critical Deaf studies: Deaf crit's analysis of unconscious internalization of hegemony within the Deaf community (Doctoral dissertation), University of California, Los Angeles.

Gallaudet Research Institute. (April 2011). Regional and national summary report of data from the 2009-10 annual survey of Deaf and hard of hearing children and youth. Gallaudet University.

Guerrero-Cantor, J. (2019). DREAMers woke: Mexican deaf women navigating college and living as undocumented (Doctoral dissertation). California State UniversityEast Bay.

Hall, W. C. (2017). What you don't know can hurt you: The risk of language deprivation by impairing sign language development in Deaf children. Maternal and Child Health Journal, 21(5), 961-965. doi:10.1007/s10995-017-2287-y

Holcomb, T. K. (2010). Deaf epistemology: The Deaf way of knowing. American Annals of the Deaf, 154(5), 471-478.

Houston, P. (1988, March 8). Deaf students shut college, demanding Deaf president. The Los Angeles Times. https://www.latimes.com/archives/la-xpm-1988-03-08mn-605-story.html

Humphries, T. (1977). Communicating across cultures (Deaf/hearing) and language learning. (Unpublished doctoral dissertation). Union Graduate School, Cincinnati, $\mathrm{OH}$.

Humphries, T., Kushalnagar, P., Mathur, G., Napoli, D. J., Padden, C., \& Rathmann, C. (2014). Ensuring language acquisition for deaf children: What linguists can do. Language, 90(2), 31-52.

Ladson-Billings, G., \& Tate, W. F. (1995). Toward a critical race theory of education. Teachers College Record, 97, 47-68.

Lawyer, G. L. K. (2018). Removing the colonizer's coat in Deaf education: Exploring the curriculum of colonization and the field of deaf education (Doctoral dissertation). University of Tennessee. https://trace.tennessee.edu/utk_graddiss/5036/

McCaskill, C. D. (2005). The education of Black Deaf Americans in the 20th century: Policy implications for administrators in residential schools for the Deaf (Doctoral dissertation), Gallaudet University. 
Journal Committed to Social Change on Race and Ethnicity | Volume 6, Issue 1 | 2020

McKay-Cody, M. R. (1998). The well-hidden people in Deaf and Native communities. A Deaf American Monograph, 48, 49-51.

Moll, L., Amanti, C., Neff, D., \& Gonzalez, N. (1992). Funds of knowledge: Using a qualitative approach to connect homes and classrooms. Theory into Practice, 31, 133-141.

Parasnis, I., \& Fischer, S. D. (2005). Perceptions of diverse educators regarding ethnicminority deaf college students, role models, and diversity. American Annals of the Deaf, 150(4), 343-349.

Registry of Interpreters for the Deaf. (2018). 2018 Annual report member services. https://rid.org/2018-annual-report/

Rosa, J., \& Flores, N. (2017). Unsettling race and language: Toward a raciolinguistic perspective. Language in Society, 46(621-647).

Ruiz-Williams, E., Burke, M., Chong, V. Y., \& Chainarong, N. (2016). My Deaf is not your Deaf. In M. Friedner \& A. Kusters (Eds.), It's a small world: International Deaf spaces and encounters (pp. 262-273). Gallaudet University Press.

Sedano, R. (2001). Traditions: Hispanic, American, Deaf culture: Which takes precedence in trilingual interpreter training? In L. Bragg (Ed.), Deaf world: A historical reader and primary sourcebook (pp. 124-128). New York University Press.

Skutnabb-Kangas, T. (2014). Afterword. In H. D. L. Bauman \& J. J. Murray (Eds.), Deaf gain: Raising the stakes for human diversity (pp. 492-502). University of Minnesota Press.

Solórzano, D., \& Yosso, T. J. (2002). Critical race methodology: Counter-storytelling as an analytical framework for education research. Qualitative Inquiry, 8(23), 23-44.

Stapleton, L. (2016). Audism and racism: The hidden curriculum impacting Black d/Deaf college students in the classroom. Negro Educational Review, 67(1-4), 149-168.

Stapleton, L., \& Croom, N. (2017). Narratives of Black d/Deaf College Alum: Reflecting on intersecting microaggressions in college. Journal of Student Affairs Research and Practice, 54(1), 15-27. doi:10.1080/19496591.2016.1204308

Strauss, A., \& Corbin, J. M. (1990). Basics of qualitative research: Grounded theory procedures and techniques. Sage.

Stuart, P., \& Gilchrist, A. (1990). A sense of identity: Deaf minorities still struggle for acceptance of their heritage. Gallaudet Today, 21, 2-10.

Tuccoli, T. (2008). Hearing privilege at Gallaudet? (Masters thesis), Gallaudet University.

Valencia, R. R. (1997). The evolution of deficit thinking: Educational thought and practice. Falmer.

Valencia, R. R. (2020). International deficit thinking: Educational thought and practice. Routledge.

Williamson, C. (2007). Black deaf students: A model for educational success. Gallaudet University.

Wu, C. L., \& Grant, N. C. (2010). Asian American and Deaf. In I. Leigh (Ed.), Psychotherapy with Deaf clients from diverse groups. Gallaudet University Press.

Yosso, T. J., Villalpando, O., Delgado-Bernal, D., \& Solórzano, D. (2001). Critical Race Theory in Chicana/o education. Paper presented at the National Association for Chicana and Chicano Studies, Tucson, AZ. 